\title{
“Hold-and-drag" closure technique using repositionable clips for large mucosal defects after colonic endoscopic submucosal dissection
}

Authors

Institution
Teppei Akimoto, Osamu Goto, Motoki Sasaki, Yasutoshi Ochiai, Tadateru Maehata, Ai Fujimoto, Toshihiro Nishizawa, Naohisa Yahagi

Division of Research and Development for Minimally Invasive Treatment, Cancer Centre, Keio University, School of Medicine, Tokyo, Japan submitted

29. March 2016

accepted after revision

5. July 2016

\section{Bibliography}

DOI http://dx.doi.org/

10.1055/s-0042-112126

Published online: 30.8.2016

Endoscopy International Open

2016; 04: E1068-E1072

(c) Georg Thieme Verlag KG

Stuttgart · New York

E-ISSN 2196-9736

\section{Corresponding author}

\section{Osamu Goto, MD, PhD}

Division of Research and

Development for Minimally

Invasive Treatment

Cancer Centre

Keio University

School of Medicine

35 Shinanomachi

Shinjuku-ku

Tokyo 160-8582

Japan

Phone: +81-3-5363-3437

Fax: +81-3-5363-3895

ogotou-gi@keio.jp
Background and study Aims: To prevent complications after colonic endoscopic submucosal dissection (ESD), we developed a new closure technique using repositionable clips.

Patients and methods: The closure of post-ESD mucosal defects was attempted in 19 cases. Mucosal defects were linearly closed by holding and dragging the anal mucosal edge towards the oral mucosal edge using repositionable clips. Standard hemoclips were additionally placed to complete the closure. We retrospectively assessed the feasibility of this technique.

Results: Defect closure was successfully completed in 18 cases (94.7\%). The mean defect size and

\section{Introduction}

$\nabla$

Endoscopic submucosal dissection (ESD) is gaining acceptance as a curative endoscopic method for gastrointestinal epithelial neoplasms with a high possibility of en bloc complete resection [1-4]. However, the technical difficulty and relatively high rate of complications because of ESD are more serious compared to those because of endoscopic mucosal resection [5].

Postoperative complications of ESD mainly include bleeding and delayed perforation. A possible cause of complications following ESD is that large mucosal defects may remain open. Several defect closure techniques have been reported to address this issue [6-9]. We developed a new technique using a repositionable clip that enables the closure of post-ESD defects quickly and accurately. In this study, we retrospectively analysed the feasibility of the new closure technique for mucosal defects after colonic ESD. the procedural time were $40.2 \pm 12.0 \mathrm{~mm}$ (range, $24-71 \mathrm{~mm}$ ) and $10.7 \pm 7.2 \mathrm{~min}$ (range, 4.0-29.9 $\mathrm{min}$ ), respectively. The mean number of repositionable clips and standard clips required for closure was $1.6 \pm 0.8$ (range, $1-3$ ) and $7.3 \pm 3.7$ (range, 3-16), respectively. No adverse events occurred during procedures and thereafter (95\% confidence interval, $0-17.6 \%$ ).

Conclusions: The new closure technique for large mucosal defects after colonic ESD using repositionable clips was feasible and appeared effective for preventing subsequent adverse events.

\section{Patients and methods \\ $\nabla$}

\section{Data collection}

The study protocol was approved by the Ethics Committee of the Keio University (Approved No. 20150049). Three expert endoscopists with experience on more than 300 cases of ESD for gastrointestinal tumors performed colorectal ESD for 32 lesions in 32 patients without a history of colectomy from February 2015 to June 2015. Considering that post-rectal ESD mucosal defects are difficult to close because of their structure being bolstered by the rectal wall, closure was not attempted in 9 cases of rectal lesions. Furthermore, 4 lesions were not attempted because of the lesion being located on the ileocecal valve (2 cases), long procedural time of preceding ESD (1 case) and the possibility of deep invasion into the submucosa (1 case). Therefore, defect closure was attempted in 19 colonic lesions in 19 patients after successful ESD. Of the 19 patients of closure, 2 patients $(10.5 \%)$ were taking antithrombotic agents. In these cases, administration of the medicines was stopped preoperatively until the antithrombotic effects disappeared, and was resumed after a few days of the procedure. 


\section{'Hold-and-drag' closure technique}

All patients were hospitalized and underwent conventional ESD as described elsewhere [1-4]. For closure of post-ESD mucosal defects, we used a repositionable clip (R-clip), QuickClip Pro (HX-202UR; Olympus Co. Ltd., Tokyo, Japan), followed by a standard hemoclip (S-clip), EZ clip (HX-610-090L; Olympus). An Rclip is composed of 2 arms that are stronger than those of an Sclip and has rotatable and open-and-close functions ( $\boldsymbol{O}$ Fig. $\mathbf{1}$ ). Post-ESD defects were closed with these clips as follows. First, we held the anal mucosal edge of the defect with an R-clip.Second, this was dragged to the oral edge of the defect by pushing the endoscope. Third, we gently reopened the clip keeping the anal edge attached to one arm of the clip, and reclosed it together with the oral edge. After confirming that the R-clip had correctly grasped both edges, we placed it. Finally, we completed the closure using S-clips to bridge the remnant gaps between both edges. When the edges were too far from one another to be closed using S-clips, even after placing R-clips, we placed additional R-clips in the same manner until the edges had sufficiently approached one another. A scheme of this closure technique is shown in $\odot$ Fig. 2.

\section{After the procedure}

The patients were allowed to drink water the next day and to have soft food two days following surgery if their physical condition, blood test and X-ray were favorable. When significant bloody stool was recognized, we defined this as delayed bleeding and performed endoscopic hemostasis. Small amounts of bloody stool were regarded as minor bleeding and were monitored without endoscopic intervention. Four days later, the patients were discharged and told to monitor whether bleeding occurred after discharge until an outpatient clinic two weeks later. When abdominal pain emerged and X-ray or CT scan showed free air in the abdominal space despite no intraoperative perforation, we defined it as delayed perforation.

\section{Data assessments}

To investigate the feasibility of this closure technique, the success rate, procedural time, number of clips required and intra/postprocedural adverse events were assessed, as well as effects of learning curve.

\section{Statistical analysis}

In the statistical analyses, Student's t-test was used for consecutive data, and Fisher's exact probability test or chi-square test was used for categorical data. Data were evaluated using JMP version 11 (SAS Institute Japan Ltd., Tokyo, Japan). Statistical significance was set at a $P$ value of less than 0.05 .

\section{Results}

$\nabla$

Of 19 lesions, 18 were successfully closed by the R-clip closure technique (94.7\%). The defect closure failed in 1 case on the sigmoid colon, wherein we were unable to drag the anal mucosal edge to the oral side because the lumen was too flexible and easily rotated coincidentally with endoscopic movement. The means of the defect size and the procedural time were $40.2 \pm$ $12.0 \mathrm{~mm}$ (range, $24-71 \mathrm{~mm}$ ) and $10.7 \pm 7.2 \mathrm{~min}$ (range, $4.0-$ $29.9 \mathrm{~min}$ ), respectively. The mean number of R- and S-clips required for closure was $1.6 \pm 0.8$ (range, $1-3$ ) and $7.3 \pm 3.7$ (range, $3-16$ ), respectively. No severe adverse events including minor

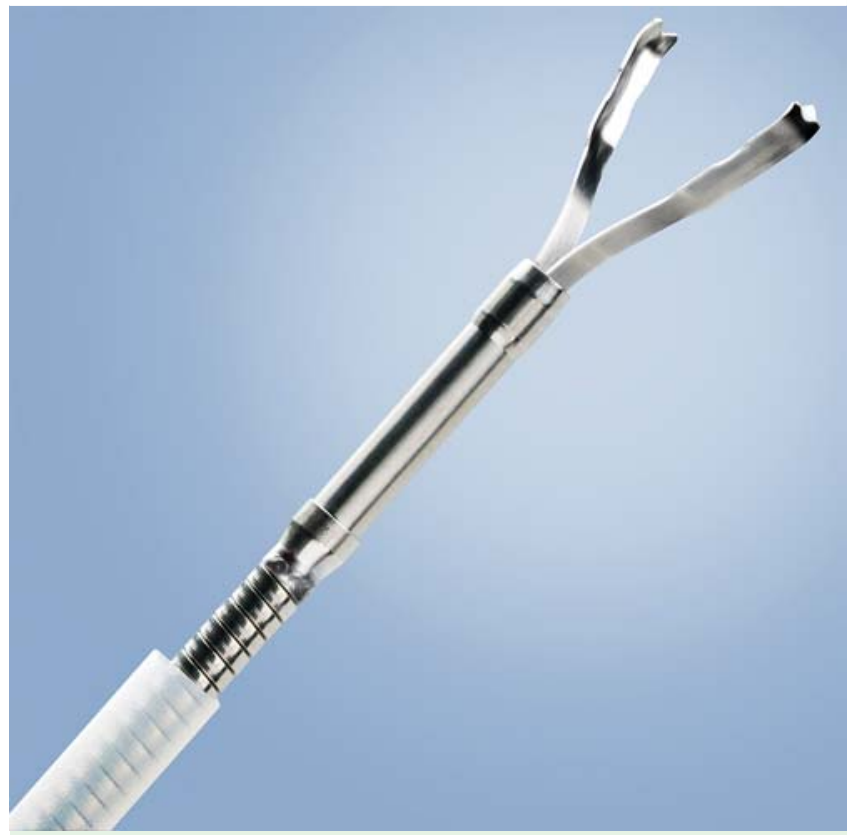

Fig. 1 A repositionable clip (Quickclip Pro $\left.{ }^{\circledR}\right)$. The clip is composed of 2 rigid blades and has rotatable and re-openable functions.

bleeding occurred during the procedures and thereafter (95\% confidence interval, $0-17.6 \%$ ). The outcome of defect closure in all attempted cases and a representative case of successful closure is shown in $\bullet$ Table $\mathbf{1}$ and $\bullet$ Fig. 3, respectively, as well as in a video ( $\bullet$ Video $\mathbf{1})$.

When the 18 cases of closure were divided into 2 groups (the first half and the second half) as shown in $\bullet$ Table 2, the number of Rclips required was significantly smaller in the second half than in the first half ( $1.1 \pm 0.3$ vs. $2.1 \pm 0.8, P=0.0028$ ), regardless of no difference in the defect size between the two groups. In addition, there was no difference in the number of S-clips, but the mean

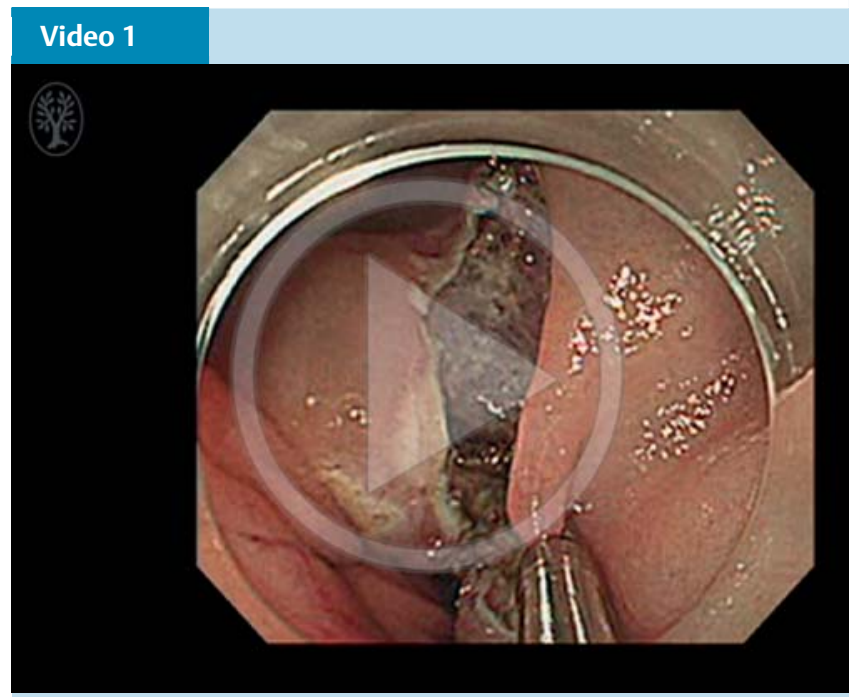

Representative case of the "hold-and-drag" closure technique. A mucosal defect is closed by holding and dragging the anal mucosal edge in the oral direction using repositionable clips. Subsequently, standard hemoclips are placed to complete the closure. Online content including video sequences viewable at: http://dx.doi.org/10.1055/s-0042-112126 


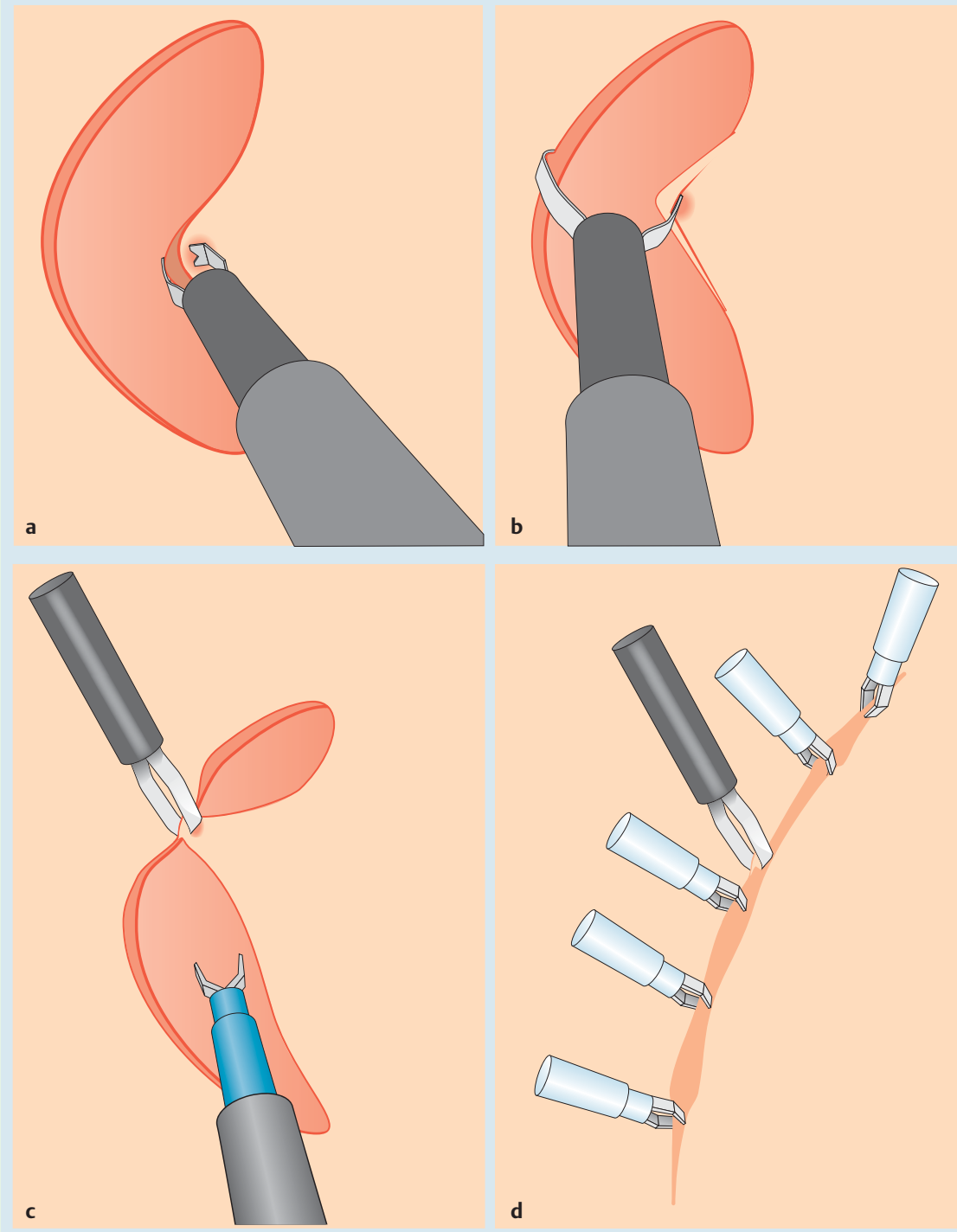

Fig. 2 Scheme of the "hold-and-drag" closure technique. a The anal edge of the mucosal defect is held with the repositionable clip (silver clip) and is dragged to the proximity of the oral side. The clip is gently reopened, keeping the anal edge attached. c The clip is reclosed over both anal and oral edges and is placed. Standard clips (blue clips) are additionally placed. $\mathbf{d}$ The closure is completed.

procedural time was shorter in the second half than in the first half $(8.3 \pm 3.3 \mathrm{~min}$ vs. $13.1 \pm 9.3 \mathrm{~min}, P=0.1643)$.

\section{Discussion \\ $\nabla$}

In this study, we demonstrate the feasibility of a newly-devised 'hold-and-drag' closure technique for large mucosal defects following colonic ESD. We also confirmed that any of postoperative adverse events never occurred after successful closure of the defects.

In order to close large mucosal defects by using only regular clips, it is necessary to place them sequentially from the outermost edges to the centre of the defect. Therefore, it requires much time and technical skills. To facilitate the closure of large mucosal defects, several techniques have been devised, for example, a looping method using an endoloop snare [6,7], a clipping method using the "8-ring" [8] and a clipping method after small mucosal incisions [9]. Although these reported techniques were effective for closing mucosal defects, the techniques require special devices/scopes or additional procedures such as mucosal incision. The "hold-and-drag" closure technique developed in this report only requires commercially-available clips and does not need special instruments or supplementary procedures. Furthermore, the high success rate of this closure method (94.7\%) implies that this technique should be easy and accessible. The procedural time for this technique would also be more acceptable compared to that for other techniques $[9,10]$. Furthermore, the number of Rclips required decreased in the second half than the first half, irrespective of the defect size. This suggests that the defect is effectively closed with fewer R-clips as the operator becomes used to this closure technique.

Whether the closure for post-ESD mucosal defects actually reduces delayed adverse events is controversial. It was reported that clip application did not decrease the rate of delayed bleeding after colonoscopic polypectomy [11,12], although the defect size in polypectomy is smaller than that in ESD. On the other hand, Liaquat et al. reported that prophylactic clipping of resection sites after endoscopic removal of lesions exceeding $2 \mathrm{~cm}$ reduced delayed bleeding [13]. Because post-ESD mucosal defects were large, defect closure after ESD should be recommended more strongly than after conventional EMR in order to prevent them.

However, it is still unknown if this closure technique effectively prevents relevant adverse events due to the small sample size in this study, although no adverse events including subclinical minor bleeding occurred. To demonstrate the efficacy of this closure 
Table 1 Outcomes of defect closure using a repositionable clip after colonic endoscopic submucosal dissection.

\begin{tabular}{|c|c|c|c|c|c|c|c|c|}
\hline No. & Age & Gender & Location & Defect closure & $\begin{array}{l}\text { Maximal defect } \\
\text { size }(\mathrm{mm})\end{array}$ & $\begin{array}{l}\text { Procedural time } \\
\text { of closure (min) }\end{array}$ & $\begin{array}{l}\text { Number of } \\
\text { R-clips }{ }^{1}\end{array}$ & $\begin{array}{l}\text { Number of } \\
\text { S-clips }{ }^{2}\end{array}$ \\
\hline 1 & 73 & M & Proximal & Succeeded & 42 & 9.32 & 3 & 3 \\
\hline 2 & 72 & M & Proximal & Succeeded & 50 & 13.57 & 3 & 7 \\
\hline 3 & 42 & M & Distal & Failed & $54^{\mathrm{a}}$ & - & - & - \\
\hline 4 & 70 & M & Proximal & Succeeded & 38 & 12.65 & 2 & 9 \\
\hline 5 & 69 & $\mathrm{~F}$ & Proximal & Succeeded & 35 & 5.50 & 1 & 5 \\
\hline 6 & 87 & M & Proximal & Succeeded & 24 & 5.40 & 1 & 3 \\
\hline 7 & 67 & $\mathrm{~F}$ & Proximal & Succeeded & 71 & 27.27 & 2 & 16 \\
\hline 8 & 79 & M & Proximal & Succeeded & 55 & 29.87 & 3 & 14 \\
\hline 9 & 77 & $M$ & Distal & Succeeded & 35 & 6.67 & 2 & 4 \\
\hline 10 & 75 & $\mathrm{~F}$ & Proximal & Succeeded & 40 & 7.70 & 2 & 5 \\
\hline 11 & 59 & M & Proximal & Succeeded & 29 & 6.77 & 2 & 5 \\
\hline 12 & 64 & $\mathrm{~F}$ & Proximal & Succeeded & 41 & 6.70 & 1 & 5 \\
\hline 13 & 56 & $\mathrm{~F}$ & Proximal & Succeeded & 50 & 11.08 & 1 & 12 \\
\hline 14 & 55 & $\mathrm{~F}$ & Proximal & Succeeded & 35 & 13.00 & 1 & 8 \\
\hline 15 & 66 & $M$ & Proximal & Succeeded & 55 & 12.92 & 1 & 9 \\
\hline 16 & 88 & $\mathrm{~F}$ & Proximal & Succeeded & 32 & 5.97 & 1 & 8 \\
\hline 17 & 72 & $\mathrm{~F}$ & Proximal & Succeeded & 25 & 5.75 & 1 & 7 \\
\hline 18 & 71 & M & Proximal & Succeeded & 31 & 8.87 & 1 & 7 \\
\hline \multirow[t]{4}{*}{19} & 67 & $M$ & Distal & Succeeded & 35 & 3.95 & 1 & 4 \\
\hline & & & & Mean $\pm S D^{3}$ & $40.2 \pm 12.1$ & $10.7 \pm 7.2$ & $1.6 \pm 0.8$ & $7.3 \pm 3.7$ \\
\hline & & & & Range & $24-71$ & $4.0-29.9$ & $1-3$ & $3-16$ \\
\hline & & & & $95 \% \mathrm{Cl}^{4}$ & $34.2-46.2^{4}$ & $7.2-14.3^{4}$ & $1.2-2.0^{4}$ & $5.5-9.1^{4}$ \\
\hline
\end{tabular}

a, Not included in the calculation of mean and standard deviation;

1 repositionable clips

2 standard clips

${ }^{3}$ standard deviation

${ }^{4}$ confidence interval.

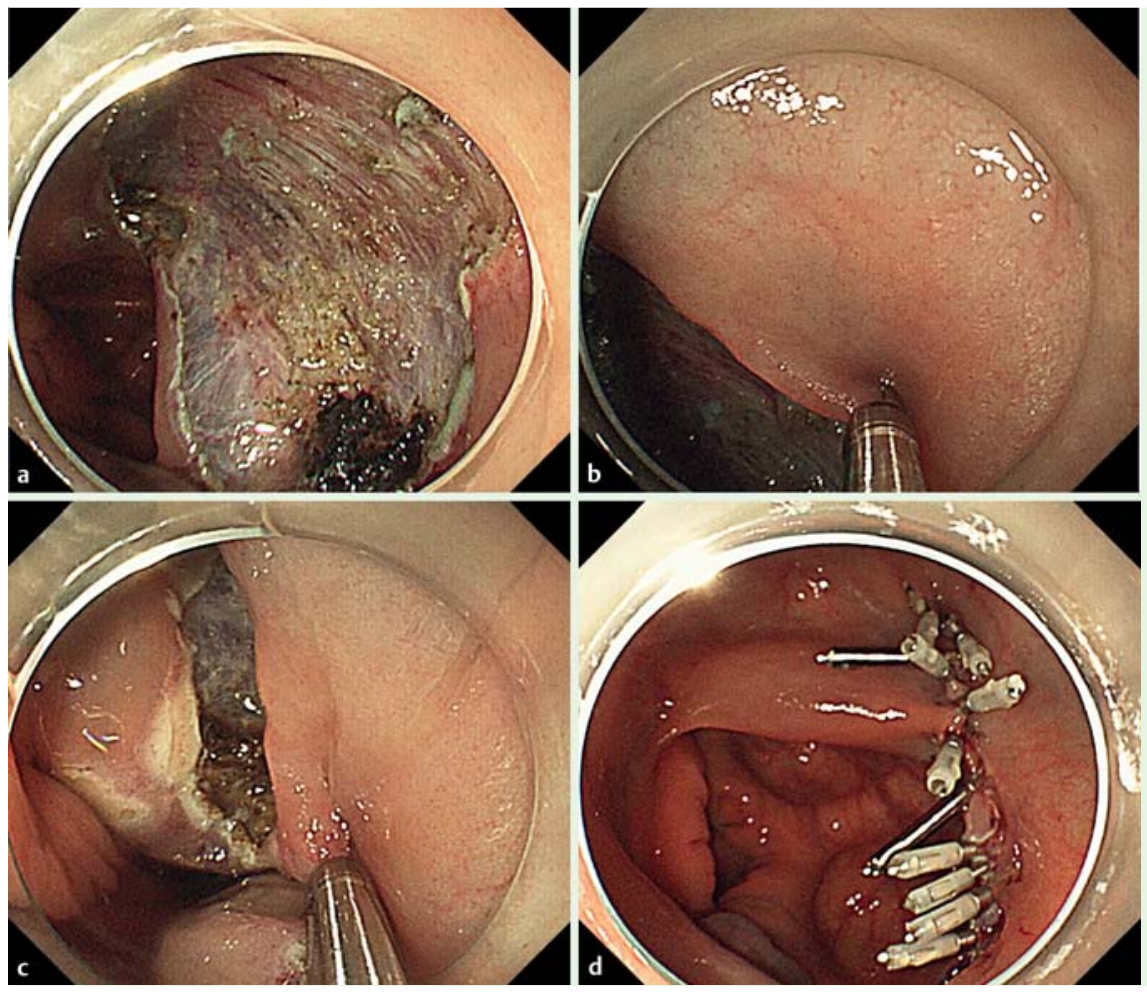

Fig. 3 Procedure of the closure technique.

a A large mucosal defect after ESD. b The anal side of the mucosal defect is held with the repositionable clip.c After gently reopening the clip and holding both edges of the defect, the clip is placed. d The closure is completed using 2 repositionable clips and 9 standard clips. 
Table 2 Comparison of outcomes according to the procedure period.

\begin{tabular}{|c|c|c|c|}
\hline & First half & Second half & $P$ value \\
\hline & $(n=9)$ & $(n=9)$ & \\
\hline $\begin{array}{l}\text { Defect size, } \mathrm{mm} \\
\left(\mathrm{mean} \pm \mathrm{SD}^{1}\right)\end{array}$ & $43.3 \pm 13.7$ & $37.0 \pm 9.9$ & 0.2776 \\
\hline $\begin{array}{l}\text { Procedural time, } \min \\
\left(\text { mean } \pm S D^{1}\right)\end{array}$ & $13.1 \pm 9.2$ & $8.3 \pm 3.3$ & 0.1643 \\
\hline The number of R-clips ${ }^{2}$ & $2.1 \pm 0.8$ & $1.1 \pm 0.3$ & 0.0028 \\
\hline The number of S-clips ${ }^{3}$ & $7.3 \pm 4.8$ & $7.2 \pm 2.4$ & 0.9512 \\
\hline
\end{tabular}

1 standard deviation

2 repositionable clips

${ }^{3}$ standard clips

technique, a comparative study should be mandatory and a large number of cases will be required because of the fairly low probability of postoperative adverse events (approximately $2 \%$ in postoperative bleeding and less than $1 \%$ in delayed perforation) [4]. Indeed, in our historical data of 57 consecutive patients who underwent colonic ESD performed by the same 3 endoscopists without closure in the past year, only 2 cases of major bleeding (3.5\%) and 2 cases of delayed perforation (3.5\%) occurred. Although this technique might hold promise for the prevention of postoperative adverse events, we focused on investigating the feasibility of the method in this study because it was a novel technique and investigation of the efficacy was thought to be premature.

In terms of cost-effectiveness, it may be reasonable to select candidates and to apply this technique only to high-risk cases of postoperative bleeding because many clips and additional procedure time were required. For example, patients with portal hypertension, intraoperative bleeding or under use of antiplatelet agents or anticoagulants would be good candidates.

This study has several limitations. First, these analyses were performed retrospectively, although the patients in the closure group were consecutively enrolled. Second, the study was conducted in a single center and the number of cases was small. Third, the operators concerned were limited to skilful endoscopists. A well-designed prospective study is required to confirm results obtained with this study.

\section{Conclusions}

In conclusion, the newly devised "hold-and-drag" closure technique using a repositionable clip for large mucosal defects after colonic ESD is feasible. Using this method, the possibility of postoperative complications may be decreased.

\section{Competing interests: None}

\section{References}

1 Ono H, Kondo H, Gotoda T et al. Endoscopic mucosal resection for treatment of early gastric cancer. Gut 2001; 48: 225-229

2 Oyama T, Tomori A, Hotta K et al. Endoscopic submucosal dissection of early esophageal cancer. Clin Gastroenterol Hepatol 2005; 3: 67-70

3 Yahagi $N$, Uraoka T, Ida Yet al. Endoscopic submucosal dissection using the Flex and the Dual knives. Tech Gastroint Endosc 2011; 13: 74-78

4 Saito Y, Uraoka T, Yamaguchi Yet al. A prospective, multicenter study of 1111 colorectal endoscopic submucosal dissections (with video). Gastrointest Endosc 2010; 72: 1217-1225

5 Cao Y, Liao C, Tan A et al. Meta-analysis of endoscopic submucosal dissection versus endoscopic mucosal resection for tumors of the gastrointestinal tract. Endoscopy 2009; 41: $751-757$

6 Matsuda T, Fujii T, Emura F et al. Complete closure of a large defect after EMR of a lateral spreading colorectal tumor when using a two-channel colonoscope. Gastrointest Endosc 2004; 60: 836-838

7 Sakamoto N, Beppu K, Matsumoto T et al. "Loop Clip", a new closure device for large mucosal defects after EMR and ESD. Endoscopy 2008; 40: E97-E98

8 Fujii T, Ono A, Fu KI et al. A novel endoscopic suturing technique using a specially designed so-called "8-ring" in combination with resolution clips (with videos). Gastrointest Endosc 2007; 66: 1215-1220

9 Otake $Y$, Saito $Y$, Sakamoto $T$ et al. New closure technique for large mucosal defects after endoscopic submucosal dissection of colorectal tumors (with video). Gastrointest Endosc 2012; 75: 663-667

10 Osada T, Sakamoto $N$, Ritsuno $H$ et al. Process of wound healing of large mucosal defect areas that were sutured by using a loop clip-assisted closure technique after endoscopic submucosal dissection of a colorectal tumor. Gastrointest Endosc 2013; 78: 793 - 798

11 Shioji K, Suzuki Y, Kobayashi M et al. Prophylactic clip application does not decrease delayed bleeding after colonoscopic polypectomy. Gastrointest Endosc 2003; 57: 691-694

12 Feagins $L A$, Nguyen $A D$, Iqbal $R$ et al. The prophylactic placement of hemoclips to prevent delayed post-polypectomy bleeding: an unnecessary practice? A case control study Dig Dis Sci 2014; 59: 823-828

13 Liaquat $H$, Rohn E, Rex DK et al. Prophylactic clip closure reduced the risk of delayed postpolypectomy hemorrhage: experience in 277 clipped large sessile or flat colorectal lesions and 247 control lesions. Gastrointest Endosc 2013; 77: 401 -407 